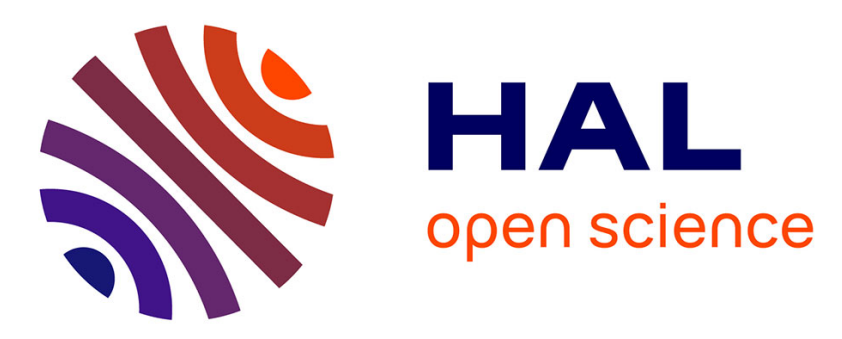

\title{
Joint Action in Didactics and Classroom Ecology: Comparing Theories using a Case Study in Physical Education
}

Chantal Amade-Escot, Patrice Venturini

\section{- To cite this version:}

Chantal Amade-Escot, Patrice Venturini. Joint Action in Didactics and Classroom Ecology: Comparing Theories using a Case Study in Physical Education. Interchange, 2015, 46 (4), pp.413-437. 10.1007/s10780-015-9263-5 . halshs-01259041

\section{HAL Id: halshs-01259041 https://shs.hal.science/halshs-01259041}

Submitted on 21 Nov 2016

HAL is a multi-disciplinary open access archive for the deposit and dissemination of scientific research documents, whether they are published or not. The documents may come from teaching and research institutions in France or abroad, or from public or private research centers.
L'archive ouverte pluridisciplinaire HAL, est destinée au dépôt et à la diffusion de documents scientifiques de niveau recherche, publiés ou non, émanant des établissements d'enseignement et de recherche français ou étrangers, des laboratoires publics ou privés. 


\title{
Joint Action in Didactics and Classroom Ecology: Comparing Theories using a Case Study in Physical Education
}

\author{
Chantal Amade-Escot \& Patrice Venturini \\ Université Toulouse Jean Jaurès, UMR EFTS
}

\begin{abstract}
This paper examines the respective contribution of two theoretical approaches to teaching and learning: the Classroom Ecology (CE) framework from AngloAmerican research and the Joint Action in Didactics (JAD) framework, which is part of French didactique research. This theoretical comparison is grounded in data from a case study in a Physical Education class in a French middle school located in an underprivileged area. Comparing how both frameworks account for classroom life (here, teaching and learning in Physical Education) enables us to uncover the unique contributions and limitations of each. As for commonalties, both frameworks examine the dynamics of teaching and learning based on ethnographic approaches. Although CE and JAD both focus on classroom settings and depict teacher-student interactions, they do not have the same background. We argue that the pragmatist and historico-cultural stances of the JAD framework have the potential for capturing in-depth the ways in which knowledge is enacted through teacher and student transactions, and therefore can help expand and deepen the CE epistemological approach.
\end{abstract}

Key-Words: Comparative Didactics, Physical Education, Joint Action in Didactics, Classroom Ecology 


\title{
Joint Action in Didactics and Classroom Ecology: Comparing Theories using a Case Study in Physical Education
}

\begin{abstract}
Introduction
As part of this thematic issue on comparative didactics, this paper examines the potential and the strength of two theoretical frameworks for analysing teaching and learning in physical education (PE): Classroom Ecology (CE) and Joint Action in Didactics (JAD). Both frameworks attempt to explain how the curriculum is enacted through teacher-student interactions. Using comparison to grasp the analytical power of these conceptual constructs enables us to perceive their commonalities as well as their differences. Moreover, comparison also enables the production of new knowledge on the incredible uncertainty of teaching and learning, which are socially and culturally bounded practices.

This discussion is grounded in a case study examining a PE badminton unit in a French middle school, which is located in a socio-economically underprivileged area. This PE case study was chosen because it is a relevant empirical example for expanding on the epistemological and theoretical comparison of the two frameworks. According to the literature, the teaching and the learning of exacting subjects in such schools always remains uncertain. For this reason, examining how each framework accounts for the enacted curriculum in such a context is of interest. Based on this case study, we contend that the JAD framework helps further develop the CE epistemological view on the importance of academic work for understanding classroom life. This view is central to the CE framework but, as we will see, has not been fully taken into account by researchers.

The following sections present first, an outline of the conceptual construction of each framework; second, the empirical case study used to examine their analytical potential; and third, a comparative discussion of their strengths, commonalties and differences. From this discussion, we then conclude that although the JAD framework has no direct connection with the CE framework, the former is better able to capture in detail the forms of knowledge that are actually learned in classroom settings.
\end{abstract}

\section{The CE and JAD Frameworks}

The CE and JAD frameworks have different origins and backgrounds. CE deals with analysing the teaching and learning process in the classroom. It belongs to the AngloAmerican research tradition on teaching and instruction (Doyle, 1986, 2006). The JAD framework studies classroom interactions with a focus on the knowledge taught and learned. It belongs to the current of French didactique research (Sensevy, 2007, 2009). Both frameworks account for how curricular content is enacted through classroom interactions; yet, their respective analytical power has never been compared in depth.

\section{The Classroom Ecology Framework}

\section{Epistemological Background}

The roots of the CE framework are found in the early research of Kounin (1970) and Gump (1969), who were inspired by Barkers's ecological psychology (Doyle 2006). For Barker (1968), human behaviour is radically situated, which means that it cannot be understood without considering in depth the context in which it occurs. Within this ontological standpoint, research focused on the teacher's work within the context of the classroom. The CE framework was also influenced by social interactionism and school ethnography (McDermott, 1977; Mehan, 1979; Wood, 1983) as well as sociolinguistic studies (Grice, 1975). In contrast to the experimental design used by the linear "process-products paradigm," which was the prevailing research approach at that time, the CE framework 
favoured in situ methods of naturalistic observation. Closely associated with the interpretative tradition of cultural anthropology, its research goal is to describe the subtle and complex processes through which concerted action, shared information and communication are established by teachers and students (Doyle, 2006). In general, the CE framework aims to provide a "central emphasis on a thorough conceptualization of situation or context in accounting for action and practice within a classroom system" (Doyle, 2006, p. 98).

During the 1970s, most of this research focused on how the context shapes the ways teachers and students interact, particularly with discipline problems (Emmer and Evertson, 1981). Taking academic work into consideration as a distinctive and determinant feature of what counts within a classroom system was Doyle's contribution $(1983,1986)$. In his famous literature review on "Classroom organization and management," he argued for expanding research in order to better understand how order is achieved in a classroom (Doyle, 1986, p. 416-418). Doyle claims that classroom order is bounded by "both the rules for social participation and the demands of academic work" (p. 424) and that "classroom management is fundamentally a process of solving the problem of order in classrooms rather than the problems of misbehaviour of student engagement” (p. 423, italics ours). Thus, the question of order in classroom should not be limited to the study of how teachers monitor students' misbehaviour or student's engagement, but should take into account how classroom management affects and is affected by the curricular content embedded in the activities and tasks. Academic work thus should be considered as a product as well as a means used to achieve order (Doyle, 1986, 2006).

\section{The Prominent Role of Academic Work and the Task System}

The central idea in the ecological approach of classroom interactions is to consider the context as a complex environment (or "habitat"), at the same time material, curricular, semantic and social (Doyle, 2006). Broadly speaking, classroom activities are intended to provide a semantic context for learning subject matter, which is why it is critical to separate managerial and instructional processes (Doyle, 1983). Studies indicate that the demands of academic work are shaped by a complex negotiation process: "activities are jointly constructed by teachers and students in time and space through processes of action, negotiation, and interpretation" (Doyle, 1986, p. 403). The major contribution of this framework is to underline that teachers track the development of content as well as the flow of social interaction; that is why Doyle claims that "subject matter needs to be included more explicitly in research on classroom management” (Ibid., p. 406). He argues that studies should better "incorporate information about the academic work that students and the teacher are trying to accomplish” (Ibid., p. 425).

In the CE framework, the notion of "curriculum enactment" is central: teachers must establish, orchestrate, and sustain jointly constituted events about a specified block of the curriculum that elicit student cooperation over a long period of time. Thus, the curriculum on the floor, defined as what students do with the content, is embodied in the tasks they accomplish under the monitoring of the teacher. Nevertheless, the task system in classrooms is fragile: "tasks involving higher cognitive processes of understanding, reasoning, and problem formulation are high in inherent ambiguity and risk for students" and consequently, for the ecological balance of classroom management (Doyle, 2006, p. 104). The higher the cognitive process required by the task is, the greater the possibility of failure since students' correct answers cannot be granted. Thus, the ambiguity and risk of each task shape students' attitudes toward the work they do and, in particular, the specific classroom ecology. This finding led researchers to better identify "the delicate balance at stake in classroom management with regard to the content embedded in the task systems” (Doyle, 2006, p. 111). To summarize, the CE framework assumes that the context of classroom settings, including 
task systems at the core of curriculum enactment, should be always taken into account to provide a better understanding of intertwined teaching and learning processes.

\section{Main Concepts and Analytical Tools}

Rooted in such assumptions, the CE framework aims at capturing "the curriculum in motion in classroom environments" (Doyle, 2006, p. 118). For this purpose, classroom ecology is described as a chronological account of action sequences within scenes. Scenes are considered as a succession of "classroom segments," organized action that surround and regulate the participants' behaviour (Doyle, 1986; Gump, 1967). This approach emphasizes the role of the activity flow (pace and momentum) during the lessons (Doyle, 1986; Kounin, 1970). To describe how curriculum is enacted through successive particular classroom segments, the CE framework provides two blocks of intertwined concepts briefly defined below: "programs of action," "primary and secondary vectors" on one side; and "negotiation," "cooperation" and "accountability" on the other.

- Program of Action Following Gump (1967), who highlighted the role of the structure of action in classroom activities, Doyle (1986) described the ecological context of each classroom through the notion of "program of action". According to Hastie and Siedentop (2006), the term "program of action" is used to identify the "place where the issues of subjectmatter content and management come together in ways that are not easily separated" (p. 215). Thus, programs of action differ across classroom segments, which are characterized by identifiable arrangements of participants and materials, specified patterns of communication, and the focal content of concern of the segment.

- The notion of vector of activity belongs the first block of concepts. It highlights the fact that the program of action is never fixed. Two types of vectors (primary and secondary) weigh on the program of action. The primary vector is about the agenda the teacher has for the lesson. It concerns the content embedded in the designed learning tasks. Doyle (1986) extends this concept by arguing that subject matter is a significant component of the programs of action in classrooms; he thus defined academic work itself as a program of action. As students may cooperate in various ways, the program of action is always negotiated and should be considered as a dynamic feature enacted through teacher and student interactions.

Similar to teachers, students have their own expectations, feelings, and personal drives about what is at stake in classroom segments (Doyle, 1986, 1992; Hastie and Siedentop, 2006; McCauthtry, Tischler and Flory, 2008). Students might also prefer to have fun, to socialize or just take it easy in class. Therefore, the secondary vector, typically initiated by students, challenges the robustness of the primary vector. It has the potential to strengthen or to weaken the dynamics of the program of action. As a result, the processes involving the two intertwined vectors are at the origin of the classroom's ecological equilibrium, which is always a delicate balance, as mentioned above. This conceptual construct of interrelated "primary and secondary vectors" that influence the "program of action" in classroom contexts drives researchers to describe classroom ecology as three interrelated systems: the managerial system, the instructional systems, and the students' social system. The former two belong to the teacher realm, while the latter is under the initiative of students. Any change in one system has distinct repercussions for the development of the others through the continuous flow of negotiation underlying the progress of the program of action (Hastie and Siedentop, 1999, 2006).

The other block of concepts (negotiation, cooperation and accountability) provides comprehensive tools for how and why the program of action changes during a classroom segment. The curricular content embedded in the tasks carries the substance of classroom events for students: it guides their attention and their attitudes toward participation and

\footnotetext{
${ }^{1}$ Typically: seatwork, recitation, small groups, etc. (Doyle, 1986, p. 399).
} 
cooperation (Doyle, 1986). Actually, the program of action is always negotiated because the students' responses vary from full engagement to passive or active non-engagement.

Negotiation This term, first identified by Wood (1983), accounts for "any attempt by students to change tasks, to change the conditions under which tasks are performed, or to change the performance standards task completion is judged by" (Hastie and Siedentop, 1999, p. 17). These negotiations have consequences in terms of the strength and durability of the primary vector of action in a particular classroom context.

Cooperation This term differs from the notion of engagement or involvement with content; it is derived from the linguistic analysis of the cooperation principle in conversations (Grice, 1975, cited by Doyle, 1986, 2006). "Order, in classrooms as in conversations, is achieved with students and depends upon their willingness to follow along with the unfolding of the event" (Doyle, 2006, p. 100). Thus, cooperation refers to the fact that classroom activities are jointly constituted by the participants in settings of enormous complexity. It also means that order in classroom may be achieved with the passive non-involvement of students who stay perfectly within the boundaries of the task but cleverly avoid learning engagement (McDermott, 1977; Tousignant and Siedentop, 1983).

Accountability is about the key role played by what counts as serious work and how teachers create and maintain students' involvement in tasks. The level of accountability drives the task systems. It determines the difference between the stated task initially provided by the teacher and the "actual" task enacted through teacher and student interactions within a classroom segment. Accountability is either teacher-controlled or content-embedded. The notion of "content-embedded accountability" emerges as a form of intrinsic accountability, which sustains classroom order through academic work, while teacher-controlled accountability should be viewed as an extrinsic way to maintain the program of action (Doyle, 2006, Hastie and Siedentop, 2006, Siedentop, 2002).

\section{The Joint Action in Didactics Framework}

The JAD framework is part of the field of French didactique following the pioneering work of Brousseau (1997) and Chevallard (1992) in mathematics education. It has been recently expanded within the comparative didactics research program including various school subjects (Mercier, Schubauer-Leoni and Sensevy, 2002; Ligozat and Leutenegger, 2012). As a descriptive framework, it accounts for the situated dimensions of ordinary teaching and learning and attempts to model human transactions as transmission of a sociohistorically built culture (Ligozat and Schubauer-Leoni, 2009). It focuses on the transactional process that occurs when a piece of knowledge is taught. As with CE, we will first summarize the JAD epistemological background and then give an overview of its concepts and analytical tools.

\section{Epistemological Background}

As part of a pragmatist and social-interactionist perspective of human activities, the JAD framework relies on the works of Blumer (1969), Goffman (1967), Mead (1934) and Vygotsky (1986). It has commonalities with Swedish didactics research, with which it shares pragmatist ideas (Quennerstedt, Öhman and Öhman, 2011; Ligozat, Wickman and Hamza, 2011; Wickman, 2012) such as understanding the semiotic process that unfolds in classroom practices (Sensevy and Forest, 2012). In this sense, the purpose of the JAD framework is to capture the enacted curriculum in detail, taking into account simultaneously the teacher, the students and the particular situatedness of knowledge content as interrelated instances. Drawing on the idea that the knowledge taught and learned and all associated meanings are co-produced by the teacher and students in culturally-bounded institutions, teacher and student practices are theoretically seen as "joint actions." However, joint action does not mean that participants have the same goals or agendas. It is for that reason that transactions 
about the knowledge at stake continuously occur in classroom settings. Studying these transactions should provide a better understanding of the dynamics of the whole process.

\section{Main Concepts and Analytical Tools}

To account for teacher and student joint actions with regard to a particular piece of knowledge, the JAD framework articulates a set of concepts and analytical tools. The concepts of "didactic milieu" and "didactic contract" refer to the transactional dynamics of the semiotic process: how individuals engage with and interpret the knowledge content at stake, and its epistemological, social and cultural dimensions. Describing these temporal dynamics, which is generically modelled as a "didactic game" (Ligozat and Schubauer-Leoni, 2009; Sensevy, 2007; Venturini and Amade-Escot, 2014), demands a fine-grained description of teacher and student actions and discourses related to the knowledge at stake. Three analytical tools account for the evolving joint action: mesogenesis, chronogenesis, and topogenesis. Four others are more specific to the teacher's actions. A brief presentation of these interrelated notions is given below.

Didactic milieu According to Brousseau (2003, p. 3), the didactic milieu is "all that acts on the student and/or that the student acts on," ideally conducive to learning. The didactic milieu thus includes material, symbolic and social objects initially provided by the teacher as a primitive set of conditions from which knowledge and associated meanings are intended to be construed through joint actions. It should be noted that this primitive didactic milieu evolves continuously because most of its components are subject to transactions. These semiotic objects have local (situational) and institutional (socio-historical) dimensions related to the knowledge at stake (Amade-Escot and Venturini, 2009), which are themselves governed by the didactic contract.

Didactic contract The didactic contract refers to teachers' and students' implicit, reciprocal and specific expectations related to the knowledge content to be studied. It can be viewed as an implicit system of mutual expectations, joint habits and attribution of intentions (Amade-Escot, 2006; Brousseau, 1997; Sensevy, 2009). The didactic contract has institutional dimensions that are perennial and local dimensions linked to the specific piece of knowledge embedded in the didactic milieu. As the content development progresses, the local characteristics of the didactic contract change, giving rise to successive breaches, some introduced by the teacher, some by students. Because the didactic contract is mostly an implicit contract, it remains silent and appears only when breaking down. This leads Brousseau to state that "the theoretical concept in didactics is therefore not the contract (the good, the bad, the true, or the false contract), but the hypothetical process of finding a contract" (1997, p. 32).

To sum up, from the JAD theoretical standpoint, students and teachers orient their actions either by co-constructing epistemic relationships with the didactic milieu or/and by using implicit class habits, both of which are forms of enacting the didactic contract. This is why didactical transactions are always bounded by a particular didactic contract and a particular didactic milieu (see Sensevy et al., in this issue). The result of these dialectic and dynamic processes - namely didactical joint action - can be described using three analytical tools (see Ligozat et al., in this issue):

Mesogenesis (i.e. genesis of the didactic milieu) documents the dynamic process by which, over time, teacher and/or student actions modify the didactic milieu.

Chronogenesis (i.e. the genesis of didactic time) documents the evolution of the knowledge proposed by the teacher and studied by the students, as it unfolds during the joint action.

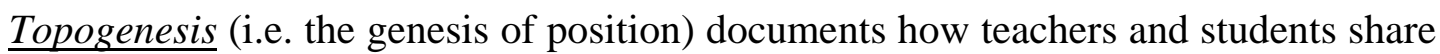
respective responsibilities all along transactions to produce the knowledge in the situation. 
These three geneses evolve in concert: "every stage of mesogenesis correspond a topogenetic state and a chronogenetic state" with regard to the knowledge at stake (AmadeEscot and Venturini, 2009, p. 29). Note that the teacher plays a lead role in these dynamics, as she or he is supposed to orient the students' actions in order to help them learn through transactions. Four analytical tools account for teachers' actions:

Definition To initiate didactic interactions, the teacher has to design a set of conditions (formerly, the primitive didactic milieu) in which the knowledge content is embedded. The students identify some ends-in-view in this set of conditions, even though they do not necessarily match the learning outcomes targeted. Thus, the teacher may remind or (re)define some aspects in relation to the intended knowledge content. Thus, actions of definition may occur over multiple transactions.

Devolution To maintain didactic interactions, the teacher acts in such a way that the students agree to establish a relationship that is as appropriate as possible to the didactic milieu and the knowledge content targeted. These devolving actions may characterise some teachers' acts during transactions.

Managing uncertainty Didactical transactions are contingent. Students do not immediately use pertinent learning strategies. Thus, teachers may actually monitor and manage the situation so that the students modify their actions in order to make them more relevant. Monitoring is a third type of action that teachers can use during classroom interactions.

Institutionalization Periodically, with the purpose of sustaining the evolution of knowledge being studied, it must be pointed out to students that they have reached a partial or complete level of the knowledge content required. By this type of action, the teacher may institute some student's actions as valuable periodically during the interaction flow.

To summarize, the JAD framework enables us to decipher the knowledge-specific transactions that occur during the didactic game. From a theoretical standpoint, it accounts for the situated interdependence of classroom actions on the one hand, and the cultural, institutional and historical contexts in which teacher and student joint action occurs on the other. As an analytical framework, it offers a relevant lens for examining classroom practice related to the knowledge at stake.

\section{Concluding Remarks on CE and JAD Frameworks}

Although this is merely a brief review of two very complex theoretical frameworks, it is clear that, while not fully compatible, they still have many points in common: an anthropological approach to the classroom setting, a focus on how the curriculum is enacted through verbal and non-verbal interactions, and attention to the intertwined processes at the core of the social dynamics of classroom life. Beyond these commonalties, we argue that the JAD framework is more accurately able to deepen our understanding of teaching and learning in relation to the content covered in subjects. This assertion is based on a case study carried out in a PE class in an underprivileged French middle school.

\section{The Case Study}

A case study offers the best way to compare theoretical frameworks and to illustrate their potential, even though generalizing from any one case is of course always delicate. Here, the case selected mainly serves to provide insight into the relevance of the CE and the JAD approaches, rather than to draw broad conclusions about education. It thus should be considered as an "instrumental case study" (Stake, 2000). For comparative purposes, the case selected is in the particular context of a school located in a socioeconomically disadvantaged area. 


\section{Comparing the CE and JAD Frameworks}

This case study is extracted from a larger research project in PE and science education conducted in a middle school in Toulouse, France (Amade-Escot and Venturini, 2009; Venturini and Amade-Escot, 2014). This school is located in a Zone d'Education Prioritaire (ZEP) which, in France, designates a governmental program to improve education in schools located in underprivileged areas. A ZEP is characterized by a high level of academic failure and student drop-out. Often combined with disciplinary and misbehaviour problems, students' engagement in learning tasks is somewhat critical. French research literature states that in ZEP schools, every uncertain action by teachers is immediately sanctioned by students' disengagement. Thus, teachers often favour immediate task achievement with the aim of encouraging students' participation. This occurs more easily when the tasks are simple and closed. However, while using simple and closed tasks may help the teacher to achieve order in the classroom, it often has the consequence that students' engagement does not lead to exacting learning (Bautier and Goigoux, 2004). These authors point out the difficulty of maintaining both learning and engagement in underprivileged schools. These findings are even more important since curricular content is always socially negotiated within the context of the school (Ainscow, 2008). From the CE approach, the search for a superficial ecological equilibrium, like creating order at the expense of enhancing learning, has consequences in terms of curriculum achievement (Doyle, 1986, 2006). From the JAD perspective, student and teacher joint action merely entails a dialectical process in terms of the quality of student engagement and learning production (Venturini and AmadeEscot, 2014).

In sum, this case study in a ZEP school is of great interest for the purpose of theoretical comparison, as it offers a teaching and learning context of uncertainty. Analysing this case through both $\mathrm{CE}$ and JAD lenses enables us to grasp the complexity of the teaching and learning process and to delve deeper into the robustness of the two frameworks.

The Context of the PE Case Study

The sections below give a brief description of the school context, the teacher and the class.

The School Environment

Located in the toughest quarter of Toulouse, this ZEP middle school has a very high turnover of students and teachers. Physical and verbal aggression among students is recurrent, thefts are frequent, and violence is common. Students are from multiple ethnic backgrounds. The district statistics reveal a high percentage of academic failure, against which the school community tries to fight within the ZEP educational program labelled "college ambition réussite."

\section{The Teacher}

Claude (pseudonym) is a 57-year old PE teacher who participated in this study from September 2005 to June 2007. The case study presented in this article concerns the teaching of badminton observed in March and April 2007. Claude has always taught in underprivileged schools since the beginning of his career and in this middle school for over ten years. He considers himself an "activist-physical educator" who worries about the social aspects of teaching in such area. He said:

"We here [the teachers of this particular ZEP school] have to make all of them [students]- all of them!- leave school with something new in their head. ...to enlarge their vision of the culture"; "to help them to integrate

\footnotetext{
2 "Collège ambition réussite": namely the term given by the French Ministry of Education to label the "ZEP education program” between 2002 and 2009.
} 
into society . . . to be ready to be in society"; "for instance now in badminton . . . whoever they are [i.e. girls and boys, high or low skilled students] I want them to know, to understand . . . how to use a racket. . .I mean tactically ... how to play with and against each other, to score properly. . . not to fight each other"; "in a word to be smart and to master a tactical overhead shot as a technique. . . not just as a shot” (excerpts from pre-unit interview).

Setting aside the difficulty of teaching in this particular context, this short excerpt points out that Claude's aim remained to reach the standards of the French national PE curriculum (MEN, 1998), which emphasized a Teaching Games for Understanding approach. ${ }^{3}$ Such an approach is demanding in terms of exacting knowledge to be taught or learned (Kirk, 2010).

\section{Class Characteristics}

The $6^{\text {th }}$ grade class was observed during a badminton unit of 8 lessons. It was composed of 17 students (8 male and 7 female). About the class, Claude said:

“... in this class, there are a lot of relational problems between individuals, they criticize each other a lot, they lose often their temper ...” ; "Relationships are already fixed, with male chauvinism, or racial attitudes either between the 'blacks' and the 'beurs'4; or against the others” (preunit interview).

\section{Method}

This section provides a brief overview of the method to indicate how the two frameworks were used.

Data Collection

Data collection consisted of: (1) a pre-unit teacher's interview; then again for each lesson in the unit; (2) a pre-lesson interview with the teacher to gain information about what was going to be taught (i.e., the knowledge content); (3) a videotape and audiotape of each lesson; (4) a post-lesson interview with the teacher. The purpose of the interviews was to access Claude’s perspectives on his teaching and on the students' learning processes.

\section{Data Analysis}

The videotape and the transcripts of verbal interactions were reviewed repeatedly to identify how individuals reacted differently and how they contributed to knowledge construction. The analysis of the video concerns all discourses and gestures by teachers and students related to the badminton-learning environments created by Claude. Narrative records of the lessons' evolution were systematically created from the videotapes and the verbal and non-verbal interactions. All the information collected was condensed into 'chronicles'. The term chronicle is used to mark the temporal features of teacher and student interactions. Its function is to grasp students' interpretation of the knowledge at stake, their engagement in learning, as well as the meaning they ascribe when playing badminton. Each lesson chronicle was established using the analytical tools of both theoretical frameworks. The lesson chronicle enabled us first, to see the evolution of student engagement and teacher reactions in

\footnotetext{
3 “Teaching Games for Understanding” is an innovative approach of game teaching in PE that tries to challenge the teaching tradition of molecularisation of content. This approach puts the emphasis on tactical knowledge within modified games. It considers that skills development and tactical understanding need to advance together, as the need for the skills becomes apparent in the course of the students' growing understanding of the game concept and developing tactical awareness (Kirk, 2010, p.51-54).

${ }^{4}$ Beurs is a French slang word used by young people to refer to people of Arabic/North African origin.
} 
terms of primary and secondary vectors of the program of action as depicted in the CE framework, and second, to identify the dynamics of the didactic contract through the evolution of the didactic milieu from the JAD framework.

In the next section, we describe the findings obtained with each framework, which served as the basis for comparing the analytical power of their conceptual constructs.

Insights on Teaching and Learning by Using both Frameworks

Because the aim of this article is to discuss epistemological and theoretical questions, examining to what extent the situated process observed is informed by the CE and the JAD frameworks, we have only briefly summarized the data. In so doing, we focus on the macro analysis of the whole unit and on the micro analysis of selected episodes during lesson 4 that we chose to support our critical reflection.

\section{From the CE Perspective}

From the data collected, the evolution of the "program of action" indicated that Claude, throughout the observed badminton unit, struggled against the second vector initiated by students who attempted to challenge the robustness of the learning tasks in terms of lack of engagement, having fun, or minor misbehaviour. Claude succeeded in maintaining classroom order at the expense of a very high level of active supervision. His permanent and systematic feed-back to individual students or groups helped them to stay involved in the classroom work. The lesson chronicles showed few episodes with disruptive student behaviour over the unit and very few off-task students, although three male students needed to be controlled all the time. In a word, struggling against the second vector enabled Claude to obtain forms of student cooperation in academic work.

Another finding highlighted by the CE framework concerns the uncertainty of academic work. Claude's lessons aimed at sustaining the primary vector by designing meaningful learning tasks. Claude provided the students with badminton tasks that were neither simple nor closed. Most of them included both cognitive and motor skills, which intended to improve students' tactical awareness through skill performance and understanding. The targeted content was to increase students' game sense of how to move the opponent in badminton play practice scenarios that stimulated the demands of the internal logic of a badminton game. These scenarios were centred on tactical and technical knowledge rather than on a molecular skill-drill approach. Tactical content-driven tasks are known to be complex to teach in terms of student monitoring. Moreover, in each lesson Claude implemented reflexive practice (as classroom segments), which is known to have a high level of ambiguity and risk for the global ecological equilibrium. This had the effect of enhancing student cooperation in the learning tasks.

All in all, Claude demonstrated considerable teaching skill in keeping students (girls and boys, high and low skilled students) engaged at a high cost of dedication and constant commitment. The use of the CE framework shows the ways in which this teacher succeeded in creating an ecology centred on meaningful badminton content which is, in regard to the literature, not so usual in underprivileged school.

\section{From the JAD Framework}

The fined-grained analysis of didactical transactions revealed a less optimistic view. The use of the JAD analytical tools uncovered a chaotic process where the dynamics of knowledge construction appeared more ambiguous due to the difficulty in maintaining the tactical knowledge over transactions. To illustrate this process, we focus on lesson 4. After a brief overview of the lesson, we examine the intended knowledge through an a priori 
analysis $^{5}$ of the primitive didactic milieu provided by Claude. Lastly, we focus on student and teacher joint-action during selected episodes.

Overview of Lesson 4 The lesson began with a 20 minute warm-up followed by a brief reminder (2 minutes) of the tactical principles of moving an opponent up and down the court, as experienced in the three previous lessons and reminded in the introduction of the new task. Claude asked the students to perform a rally of multiple shuttlecock shots within a particular play practice (Figure 1). His main didactical intention for the unit was that students enlarge their badminton game sense of how to move the opponent and thus create an open space to score a wining point: "I want the students to understand how to force the player to move, how to create an open space on the opponent's court." (pre-unit interview). The three previous lessons focused on how to create space by moving the opponent up and down on half-width, normal single badminton courts. Here, in lesson 4, the focus was to create space by moving the opponent laterally. For this purpose, the primitive didactic milieu defined by Claude at minute 22 consisted of players " $\mathrm{A}$ " and "B" maintaining the shuttlecock in the air during a lasting badminton rally involving two different court sizes (Figure 1): "A" plays on a normal single court, "B" plays in a wider (double court width) and shortened court. 18 minutes were dedicated to this play practice. Then, Claude gathered all students in the middle of the gymnasium for a 6 minute discussion on the theme: "How to produce a high overhead clear shot?" The lesson ended with one-on-one games (22 minutes), in which the students were asked "to collect the scores of the matches" (Claude's discourse), after which, the students were asked to help put away the equipment in the gymnasium.

A Priori Analysis of the Primitive Didactic Milieu The knowledge to be learned in this lesson for player " $\mathrm{A}$ " is to create open space by moving her/his opponent player " $\mathrm{B}$ ".

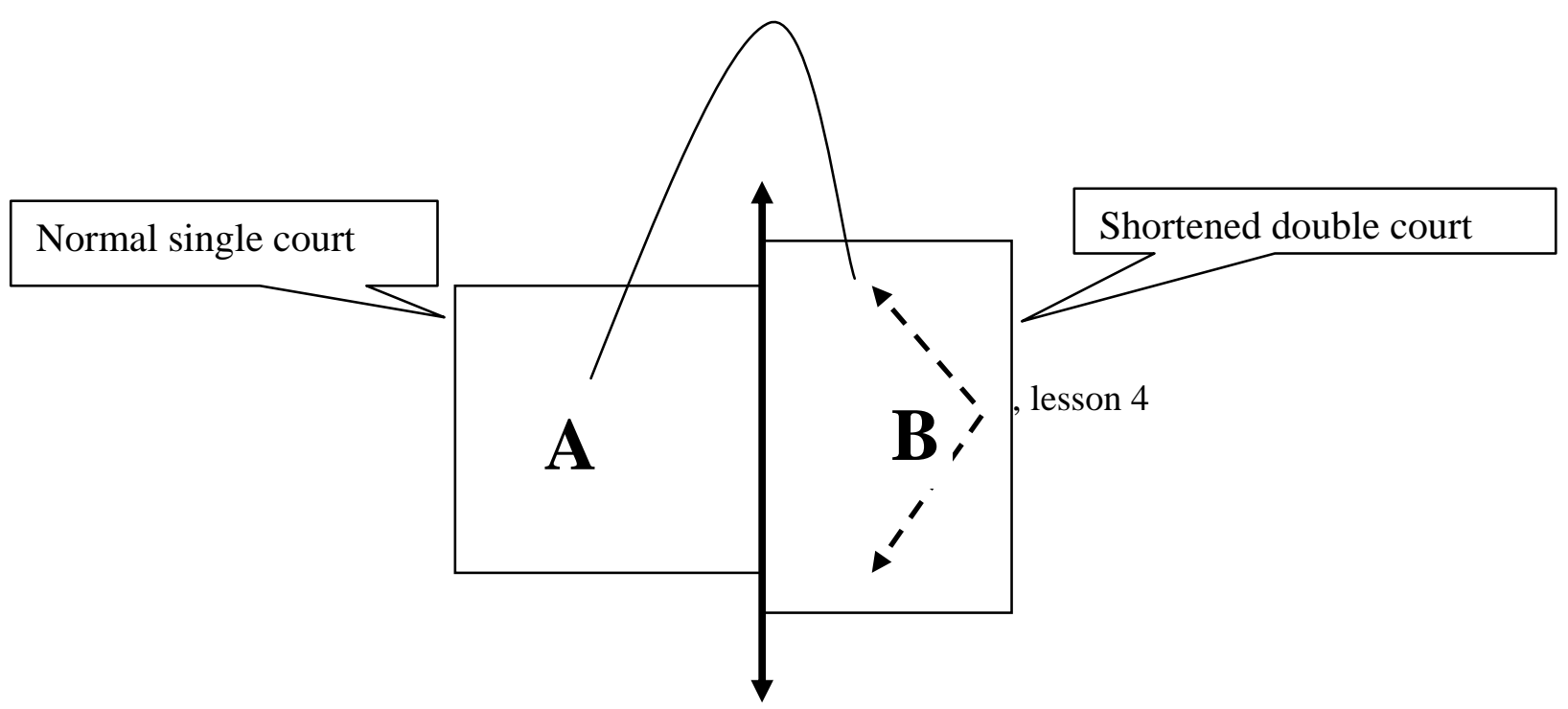

The strategy for " $\mathrm{A}$ " is to produce tactical overhead clear shots that move the opponent left to right. As for "B", she/he has to return the shuttlecock to "A", so the rally can continue. In fact, there is a twofold knowledge at stake embedded in this primitive didactic milieu: tactical knowledge (for " $A$ " to move the opponent " $B$ "; for " $B$ " to defend a width court by using moves and repositioning), and technical knowledge linked to the tactical one (for both players to perform tactically, one needs to produce a skilled overhead clear shot with

\footnotetext{
${ }^{5}$ An a priori analysis seeks to give a view on the epistemic sense of what is at stake during a didactical transaction: what is the content knowledge embodied in the primitive didactic milieu? Its exploratory function is to anticipate the students' possible strategies. Within the JAD framework, an a priori analysis is a crucial step for depicting the co-construction of content that occurs during didactic transactions.
} 
a high shuttlecock trajectory to make the rally collectively possible). The knowledge here concerns an epistemological move ${ }^{6}$ within the logic of the badminton game, which is to create the ability to mark a point by making your opponent move. It should be noted that this knowledge content is not formally embedded in the primitive didactic milieu, since its goal is to produce a cooperative rally and not to score points. The knowledge under consideration would appear later in the lesson, when students had to play the real game (the one-on-one at the end of the lesson). Nevertheless, this epistemological move is already a premise here, as indicated by Claude's early definition of what he expected from his students (didactic contract): "hey guys, if you always shoot the ball in the direction of your opponent, you have seen (previous lesson) that you never scored ... now the game is to make her/him run a little... ok!" (Claude's discourse). In fact, the knowledge at stake is to identify the tactical conditions that allow player " $A$ " to produce overhead clear shots that move player "B" left and right on the opponent's side of the net. However, the layout of this primitive didactic milieu is insufficient to create the conditions for attaining the twofold kinds of knowledge. For example, if a player cannot produce a high shuttlecock trajectory that gives enough time to the other player, the rally cannot go on. This is even more difficult for "B" because of her/his moves and repositioning on the wider court put her/him in an unsteady body balance that affects the production of shuttlecock trajectories. In such conditions, the knowledge in view may disappear and the didactic milieu fades. What is happening during the teacher and student joint action?

Joint Action Analysis during Play Practice Claude's definition of the primitive didactic milieu lasted six minutes. At minute 28 of the lesson, the students began to play, while Claude moved around the seven courts of the gymnasium monitoring each group of two players. During the 18 minutes of play practice, the didactic milieu evolved in different ways for different students. Through the teacher and student joint action, a subtle mesogenesis slightly appeared. For example: (1) some students favoured the rally at the expense of the opponent player's move. They pushed the shuttlecock in front of the head, engaging themselves in an economical strategy that did not allow them to move player "B"; (2) a few students played against the opponent using net drop (more or less deliberately); (3) some others could not keep the rally going because of low shuttlecock trajectories. These examples illustrate how breaches of the didactic contract appeared and modified the content at stake through students' actions.

Some others breaches of the didactic contract were introduced by the teacher progressively throughout the class when he observed that students were not able to maintain the rally. First, Claude asked students to slow down their play. This request was at the core of the didactical transactions during the first minutes of the play practice. He repeatedly explained that the shuttlecock trajectory should be high to give each player enough time to assess the opponent's positioning. He went from court to court and emphasized the shuttlecock trajectory with students: "play high, high!” When a student performed a high trajectory, he praised each successful attempt: "Good Soraya! That's what I call a high trajectory! When you play high, you give yourself time to move and to take up your position again! That's the clue" (minute 32). Most of his institutionalizing discourse concerns this facet of the knowledge content required. For example, during play practice, the data shows that the subject of trajectories' height was continuously repeated through different verbal forms ("high!, high!” ; "I go, I hit the shuttlecock high, I reposition” ; "remember we said to play the shuttlecock high!” ; "higher otherwise you won’t be able to do a long rally”) and/or

\footnotetext{
${ }^{6}$ We borrow this notion from Lidar, Lundqvist and Östman (2006) to point out the knowledge at play during the transaction. For these authors, epistemological moves concern what the teacher indicates in her/his action to make students aware of what knowledge is relevant and which ways of making meaning are valid in a specific educational context.
} 
gestural demonstrations. Claude monitored each group of two players very closely, always pointing out the positive effect of a high shuttlecock trajectory and giving students institutionalizing tips. Yet, he also intervened in order to control student behaviour to prevent disruptions: "In this class, students must always be controlled, especially boys, I don't like to let them play alone, they should be praised all the time, otherwise they give up" (post-lesson 4 interview). Nevertheless, students' difficulties in maintaining a long rally despite Claude's monitoring led to a slight change of the didactic contract. This opened up the way for another type of didactical transaction, as examined below.

Gradually, the effect of Claude's discourse when monitoring students' was to make the real content slightly evolve from a tactical goal to a focusing on the physical technique, which is the badminton overhead clear shot. In fact, to perform a high overhead clear, the shuttlecock has to be hit behind the head, with the racket strings oriented to the height. This means that students change their body posture and positioning, which is also a part of the targeted knowledge. Claude then showed the correct movement, reinforcing his verbal clues with non-verbal demonstrations. In so doing, Claude progressively reduced the uncertainty of the didactic milieu. However, and at the same time, he still questioned some students about the tactical use of the badminton overhead clear, in order to make them reflect: "How to give time to my partner? Franky: how do you produce high shuttle trajectories?”; "Khaled, where do you have to hit the shuttlecock if you want to it to go high? (minute 39 to 41). Thus, Claude was torn between the conflicting goals of maintaining the intended knowledge content, and having the class learn something; in the end, the intended knowledge content had to be reduced.

To summarize, using the JAD framework brings to light the ongoing knowledge coconstruction through tiny chronogenetic moves. The consequences, over the course of the didactical transactions, were that the content knowledge was enacted through continual breaches of the didactic contract. This phenomenon is illustrated through the didactical transactions that continued to occur right after the 18 minutes of play practice.

Joint Action Analysis During Class Discussion Claude gathered all students around him to give them opportunities to reflect on the tactical dimension of the game they had just played. The six-minute discussion expressed the uncertainty of the didactical transactions as shown by the extract below:

343. Claude: Thus, this small game here... It can be done, it can function only if you hit the shuttlecock high! So we're gonna ask again, any ideas why? Because we all see that some of you guys aren't hitting the shuttlecock so they have high trajectories. Why? Why was it hard to make high shuttle trajectories? Franky, why is it difficult to produce high trajectories?

344. Franky : Because we didn't hit the shuttle strong enough?

345. Claude: No it isn't a question of strength!

346. Franky : because we don't shoot ...

347. Another student : no

348. Another student : because he shoots like this (showing the serve skill) and not like this (showing the movement of an overhead clear)

349. Claude: no this is the serve, but you might find the solution using the serve also! Then what you have to do? ...I saw some of you playing with the racket in front of your nose; it looks like they are afraid not to see the racket and the shuttlecock. But look at me, this is what I want you to do (in front of all students Claude showed a perfect shuttlecock overhead clear, with the racket far behind his head, and the wrist high) I put my racket behind my head, the strings up to the ceiling ... Why? 
350. Soraya: should get up speed

351. Claude: No!

352. Ayoub: To hit high ...

353. Claude: so...

354. Ayoub: we should

355. Claude: So you must ... and you should have found it earlier, that to produce a high shuttlecock trajectory, you must hit it from under ... and thus all of you are not under the shuttlecock enough when hitting, not enough under to make it lift. To make the shuttlecock lift, you do have to hit it with the racket behind your head, strings up!

This excerpt points out Claude's overhung 'topos' built around a questioning sequence whose format is initiation - response - evaluation. The chronogenesis is conducted by the teacher, and students are given little authority in solving the problems themselves. Claude's discourse aimed to elicit, through the systematic rejection of the non-expected response, the one which supports the teacher's view of the right answer. Yet, this analysis also reveals how the content knowledge at stake has changed. The initial tactical issue of the game fades away, giving way to another knowledge content that is less tactically demanding but necessary for continuing both the game (the rally) and the didactic relationship. The data supports this interpretation, that during this critical sequence initially dedicated to foster game understanding, Claude's teaching strategy - in this underprivileged school - was to avoid disruptive behaviours by monitoring the students very closely either during their play practice as well as when he wanted them to reflect:

during the lesson, if I leave them free, they can get out of hand. Because here [in this school] discipline and strictness are mandatory; and moreover ... there is respect of the other (post-lesson 4 interview).

The detailed analysis of the specific knowledge evolution during teacher and student joint action underlines how maintaining exacting content is uncertain and subject to diverse form of transactions. In these transactions, the intended initial knowledge may be simplified and watered down, as well as the intended opportunity to devolve it to students.

To summarize, the JAD bottom-up analysis of PE in an underprivileged school reveals how teacher-driven chronogenesis and topogenesis contribute to learning the kinetic movement of the overhead clear at the expense of its tactical meaning. The ongoing joint action made the tactical goal progressively disappear, to the benefit of more fragmented knowledge content. In fact, in this lesson the teacher recognized certain patterns of activities and thus monitored students in such as way so that these patterns made the didactical transactions continue, while avoiding disruptive actions. Finally, real content knowledge was a by-product of the co-constructed mesogenesis, which consequently, in this specific case, helped maintain the didactical relationship at the expense of the tactical knowledge content initially intended.

\section{Discussion}

After this brief overview of the findings, we will now return to the broader aim of this article: comparing two theoretical and analytical approaches as ways of better understanding the logic of classroom practices, as well as teaching and learning in relation to curriculum choices. Discussing how different frameworks intersect and how they are compatible, their respective strengths and weakness, as well as clarifying their epistemological stances remains a major issue for comparative didactics (Wickman, 2012). In this section, we examine the relevance of the CE and JAD frameworks by first, outlining their 
commonalties and their main contributions, then, by exploring their ontological, conceptual and methodological dissimilarities.

\section{CE and JAD Frameworks: Commonalties and Primary Relevance}

Through both theoretical lenses, the badminton case study confirms that teaching and learning practices occur in environments that are complex, uncertain and unstable. In this underprivileged school, the use of both research frameworks shows that order in the classroom is content dependent, and that discipline and content are interwoven in ways that are not easy to untangle. Both approaches provide considerable insight into how teaching, content, learning, and the environment interact and how they are interconnected. Moreover, both approaches highlight that knowledge in a classroom is co-constructed through teacher and student interactions.

Nevertheless, because of their different foci, each framework emphasizes certain specific aspects of teaching and learning practices. Specifically, the CE framework takes into consideration how student activities impact academic work in the classroom. In short, ecological studies establish how the students' social system influences the dynamics of content development through different forms of student action, negotiation, and interpretation, as briefly pointed out in the case study. Recurrent results suggest that students' learning paths are influenced by a variety of backgrounds, situational factors and social issues ${ }^{7}$ (Doyle, 1992, p. 505-507; McCauthtry, Tischler and Flory, 2008).

As for JAD, it focuses on how teacher and student joint actions impact the in situ process of knowledge production in terms of student learning outcomes (Amade-Escot, 2000, 2006; Amade-Escot, Elandoulsi and Verscheure, 2015; Leutenegger and Schubauer-Leoni, 2002; Ligozat, Wickman, and Hamza, 2011; Verscheure and Amade-Escot, 2007; Venturini and Amade-Escot, 2014). For this purpose, the JAD approach gives special attention to the specific knowledge content at stake, how it is embedded in the primitive didactic milieu, and how it evolves during didactical transactions.

To summarize, the badminton case study supports the idea that although both frameworks attempt to decode how the curriculum is enacted in classroom settings, JAD provides tools for analysing the epistemological features of the content taught, while CE has a broader focus on the curriculum content at stake without indicating how to depict that content in its relation to the task system in which it is embodied. Broadly speaking, the CE framework does not deal with this aspect in detail. As a result, researchers using this approach may overlook some of the intricate details of content issues and pedagogical processes.

\section{CE and JAD Frameworks: Sketching out their Differences}

In this section, we posit that $\mathrm{CE}$ is a broad framework about teaching and learning (i.e. how teachers support student work in their attempts to reach the curricular content), while the JAD framework proposes a content-knowledge related approach to understanding what happens in classrooms. To support this argument, we examine the ontological, conceptual and methodological differences of both approaches successively.

\section{CE and JAD Ontological Standpoints}

The CE framework emerged in the late 1970s in North America, at the peak of positivist research on teaching effectiveness. Doyle's proposal, referring to "Dewey's pragmatist philosophy of educational science as a means of gaining an understanding of the social complexities of education in its concrete forms" (1992, p. 489), was to introduce an alternative way of studying classroom life with a greater affiliation with sociological and anthropological traditions of understanding human activities (Siedentop, 2002). Even though

\footnotetext{
7 "Social issues such as caring, emotional connections, race, gender, sexuality, and many others directly impact the ecology of physical education classrooms” (McCauthtry, Tischler and Flory, 2008, p. 281).
} 
the purpose of the ecological approach was an attempt to challenge mainstream positivist research on teaching, most studies focused on uncovering 'the' right ecological class equilibrium that would determine 'right' teaching. This ultimate goal of the CE perspective may be seen through its continuing ambition to improve teaching effectiveness (Doyle, 1983, 2006; Hastie and Siedentop, 1999; McCauthtry, Tischler and Flory, 2008).

The JAD framework derived from subject didactics, which in the early 1970s focused on the conditions for knowledge to be taught and learned, in the light of the intrinsic nature of knowledge and its actual function in social practice. Breaking from this structuralist viewpoint (Ligozat and Schubauer-Leoni, 2009), studying teaching and learning specific knowledge as "joint actions" was first outlined by Schubauer-Leoni (1986). At the same time, emerging didactic research in PE demonstrated that content knowledge appears through the flow of implicit interactions that occur between students and teachers all along their many attempts to achieve the instructional goals of the task through shared practice (Marsenach, 1989). Looking at classroom practices as being organically constituted through cooperative actions between participants, the JAD framework seeks to take into account the 'situatedness' of teacher and student transactions concerning the transmission of a socio-historically built culture. This framework acknowledges the idea that student learning occurs within the unavoidable tension between individual agency and the cultural, institutional and historical contexts of the activity. It thus offers a new perspective that clearly belongs to the anthropological tradition in social sciences (Ligozat and Schubauer-Leoni, 2009).

In sum, the JAD framework takes a descriptive, pragmatist view of teaching and learning as interwoven practices (Wickman, 2012), while CE still has links with teacher effectiveness.

\section{CE and JAD Conceptual Constructs}

Compatibility between these two conceptual constructs has been discussed elsewhere (Amade-Escot, 2000; Hastie and Siedentop, 2006; Leriche, Desbiens, Amade-Escot and Tinning, submitted), explaining their common ethnographic approaches to classroom interactions and examining some potential implications for research. Our aim here is to point out, in addition to their possible compatibility, some of their conceptual dissimilarities in light of this thematic issue on comparative didactics.

Connected with Wood's idea (1983) that most classroom events are the results of teacher and student continuous "negotiations", the CE theoretical construct focuses on the tension between the "teacher-driven primary vector" and the "secondary vector which is driven by the student's social system" (Hastie and Siedentop, 1999, 2006). In the ecological perspective, the tension between these two vectors should be monitored by the teacher in order to maintain the "program of action," that is, to obtain an "ecological class equilibrium" focused on learning (Doyle, 1986; Hastie and Siedentop, 2006).

However, since the concept of didactic contract highlights the incredible uncertainty of teaching and learning, it is undoubtedly more accurate and less general in accounting for the type of negotiations that affect the forms of knowledge actually taught and learned (i.e. the curriculum in motion). Moreover, we would point out that the central notion of unavoidable breaches of the didactic contract (Brousseau, 1997) is not present in the CE concept of negotiation. The latter encompasses the idea that "good" teaching implies effective teacher monitoring of the negotiations so that the academic purpose of the curriculum is not (or less) circumvented by the students' social system. On the contrary, what is central in the JAD conceptual construct is to consider the dynamic processes of finding a hypothetical didactic contract (Brousseau, 1997). Therefore, breaches of the didactic contract are not signs of dysfunction, but should be considered as intrinsic events in the ordinary and uncertain processes of teaching and learning any particular knowledge. This theoretical discrepancy is 
an important aspect that enhances the pragmatist view of the JAD framework, which considers classroom events as human transactions in a Deweyian sense.

Conversely to the didactic contract, the didactic milieu in the JAD framework is far broader than that of academic task in CE. Stressing the continuous co-construction of meaning by each participant (see the notion of mesogenesis), the concept of didactic milieu encompasses all that is collectively produced over transactions through teacher and student joint actions, as well as the institutional and cultural meanings related to the socio-historic perspective of knowledge (Amade-Escot and Venturini, 2009; Ligozat and Schubauer-Leoni, 2009). These aspects are not explicitly mentioned in the ecological approach, even though we can consider they implicitly belong to the task system ${ }^{8}$. In more recent work, links between the CE approach and Vygostkian activity theory were pointed out (Doyle, 2006, p. 119-120), referring to the idea that meaning-making in academic tasks is culturally and historically situated. However, very few studies have been done that expand upon this perspective ${ }^{9}$, and for lack of space here we are unable to go into greater depth about these arguments. Suffice it to say that they support the idea that JAD can be considered as a framework that extends CE's purpose of having an integrated conception of curriculum and pedagogy (Doyle, 1992), by making detailed and specific accounts of the processes by which knowledge is experienced and constructed in situ by teachers and students.

\section{CE and JAD Analytical Tools}

From a methodological viewpoint, both approaches examine the dynamic evolution of teaching and learning based on empirical observation of a series of lessons, sequencing the classroom videos into units of analysis: "classroom segments" in the CE approach (Doyle, 1986; Gump, 1969); "didactical transactions” in the JAD approach (Tiberghien and Venturini, 2015). Both analyse discourse and gestures throughout the lessons using analytical tools in order to capture the interwoven actions of students and teachers. Both account for the intricate process of enacting the curriculum in everyday classroom life.

Nevertheless, in order to explain the dynamics of classroom events, CE and JAD frameworks envision differently the way curricular knowledge is enacted through classroom interactions. As for the methodological recommendations of each framework, we consider that cutting out "classroom segments" (defined by Doyle, 1986, p. 399 as: "seatwork, recitation, small groups and cooperative learning team, transitions") has a broader span than "didactical transactions," which are specifically related to the knowledge content at stake (i.e. in the case study, the transactions about the relevant signs of a high badminton overhead clear). For instance, in the CE approach, the analytical tools of negotiation, cooperation and accountability in the managerial, instructional and students' social interrelated systems during a classroom segment provide a description of the unstable equilibrium of classroom ecology which is, most of the time, at the expense of instructional objectives (Hastie and Siedentop, 2006; Siedentop, 2002). This type of analysis stresses the need for strong teacher supervision when orchestrating classroom activities that favour and sustain students' accountability in academic tasks.

From the JAD perspective, the focus on the triadic relationship (teacher, students, and content) during didactical transactions considers the individual and the environment as being mutually defined and interdependent. For instance, the mesogenesis, chronogenesis, and topogenesis analytical tools account for actions that are fundamentally context- and contentdependent. They are also relational tools in themselves, as they are suitable for decoding

\footnotetext{
${ }^{8} \mathrm{CE}$ researchers describe academic tasks in terms of the cognitive operations involved (i.e. memory, routines and algorithms, expression toward content, understanding) and the degree of task complexity (see Doyle, 1992 and in PE, Rink, 1994), but they never address the specificities of the knowledge content at stake.

${ }^{9}$ Except some works using the CE framework to analyse Sport Education curricula in PE (Hastie \& Siedentop, 2006)
} 
teacher and student joint actions whether the action is initiated by the teacher and/or the students. Here, too, there are indications that the pragmatist and situated perspective of the JAD approach provides access to classroom life without losing sight of the specific content taught and learned.

Actually, as shown in the case study, "a priori analysis" provides an overview of "the epistemic tasks that are embodied in the teaching materials that the teacher uses" (Ligozat and Schubauer-Leoni, 2009, p. 91). Modelizing the knowledge embedded in the didactic milieu through a priori analysis is a key to describing and understanding: what is really taught and learned; what meanings objects and situations may have for the participants throughout their joint actions; and the distance of these meanings from the referent knowledge in view (such as the critical tactical sense of the overhead clear in the badminton task analysed). Scrutinizing the epistemological density of didactical transactions as we have done using the JAD framework enables thorough descriptions of classroom practices.

\section{Conclusion}

Epistemological comparison of theories anchored in different trends or research traditions is an undertaking fraught with risk; even more so when based on a single case study. Nonetheless, this study has been able to show that CE and JAD are both relevant frameworks for grasping teaching and learning complexity in ordinary classroom. Although there would seem to be considerable affinity between these frameworks, they should be considered as two different lenses. The ecological approach gives an overview of class equilibrium, student engagement and off task periods, opportunity for practice and overall learning outcomes, while the didactique approach gives a glimpse of the epistemological moves enacted in a classroom through the complex and chaotic dynamics of teacher and student interrelated activities. Exploring their respective strengths through empirical analysis of a case study has shown that, while the CE and JAD frameworks share a common interest in curriculum enactment in classroom settings, they do not have the same perspective. In terms of commonalties, both frameworks examine the change in dynamics of teaching and learning from an anthropological stance. Yet, as we have seen, due to JAD's ability to capture in detail the dynamics through which curricular knowledge is enacted, we contend the pragmatist and historico-cultural standpoint of JAD's conceptual construct helps deepen the epistemological program of the CE framework. Although additional research on the CE framework has been done after the original founders, unfortunately it has not developed this aspect further, to provide a more refined analysis; using the contributions of the JAD framework may help CE do just that. For example, in PE, most research using the CE approach does not focus on the epistemological facets of knowledge when accounting for classroom events. This article has shown how using the JAD approach can complement and fill this gap in CE.

The strength of the JAD framework lies in its ontological, theoretical and methodological stances that enable a more profound understanding of the enacted process of knowledge co-construction. Within a "bottom-up analysis of the didactic transposition" (Schubauer-Leoni and Leutenegger, 2005, p.420), studying didactical joint action gives a detailed account of the dynamics of the evolution of content knowledge in the classroom (in our case study: reducing the tactical sense behind a certain move in badminton practice - the grammar of the game - to a description of decontextualized movement).

Finally, the JAD perspective acknowledges a twofold assumption: (1) knowledge construction at school is a result of social interactions related to the values, the beliefs, the embodied emotions, and the ways of knowing that learners and teachers bring to bear on any classroom activity, and (2) at the same time, classroom activity works with referenced knowledge, which is socio-culturally bounded and recognized by an institution as adequate 
knowledge for fully participating in its own social activities (Amade-Escot and O'Sullivan, 2007, Ligozat and Schubauer-Leoni, 2009).

More broadly, in certain ways this article pursues the reflection initiated by Wickman (2012) when he compared the Swedish and French schools of didactics, that is, to examine the potential power of different research traditions in studying classroom interactions and how they influence what the students are able to learn. In the case studied here of a badminton unit in an underprivileged school, we can say that comparatism in didactics is also a way to produce knowledge that reveals the incredible uncertainty of teaching and learning subject content in ordinary settings.

\section{References}

Ainscow, M. (2008). Teaching for diversity. The next big challenge. In F.M. Connely, M.F. He \& J. Phillion. The Sage Handbook of Curriculum and Instruction (pp. 240-258) Los Angeles, CA: Sage Publications.

Amade-Escot, C. (2000, April). How students manage the didactic contract? Contribution of the didactic perspective to research in physical education classroom. Paper presented at the 2000 AERA Congress, New Orleans, April, 24-28, USA. (ERIC Document Reproduction Service $N^{\circ}$ ED442786)

Amade-Escot, C. (2006). Student learning within the didactique tradition. Chapter in D. Kirk, M. O'Sullivan \& D. Macdonald (Eds.). Handbook of Research in Physical Education (pp. 347-365). London, Thousand Oaks, New Delhi: SAGE Publications Ltd.

Amade-Escot, C., Elandoulsi, S., Verscheure, I. (2015). Physical Education in Tunisia: Teachers' Practical Epistemology, Students’ Positioning and Gender Issues. Sport, Education and Society, http://dx.doi.org/10.1080/13573322.2014.997694

Amade-Escot, C. \& O’Sullivan, M. (2007). Research on content in physical education: theoretical perspectives and current debates. Physical Education and Sport Pedagogy, 12(3), 185-203.

Amade-Escot, C. \& Venturini, P. (2009). Le milieu didactique : d'une étude empirique en contexte difficile à une réflexion sur le concept. Education \& Didactique, 3(1), 7- 43.

Barker, R. G. (1968). Ecological psychology. Stanford, CA: Stanford University Press

Bautier, E. \& Goigoux, R. (2004). Difficultés d'apprentissage, processus de secondarisation et pratiques enseignantes : une hypothèse relationnelle. Revue Française de Pédagogie, 148, 89-100.

Blumer, H. (1969). Symbolic Interactionism. Perspective and Method. Berkeley, Los Angeles, London: University of California Press.

Brousseau, G. (1997). Theory of Didactical Situations in Mathematics. Dordrecht: Kluwer Academic Publishers.

Brousseau, G. (2003). Glossary of some concepts belonging to the theory of didactic situations in mathematics. http://pagesperso-orange.fr/daest/guybrousseau/textes/Glossaire_Brousseau.pdf

Chevallard, Y. (1992). Fundamental concepts in didactics: perspectives provided by an anthropological approach. In R. Douady and A. Mercier (Eds.), Research in 
Didactique of Mathematics, Selected Papers (pp. 131-168). Grenoble: La Pensée Sauvage.

Doyle, W. (1983). Academic Work. Review of Educational Research, 53(2), 159-199

Doyle, W. (1986) Classroom organization and management, In M.C. Wittrock (Ed.) Handbook of research on Teaching (pp. 392-431). New-York: Macmillan, $3^{\text {rd }}$ Ed.

Doyle, W. (1992). Curriculum and pedagogy. In P. W. Jackson (Ed.), Handbook of research on curriculum (pp. 485-516). New-York: Macmillan.

Doyle, W. (2006). Ecological approaches to classroom management. In C. Evertson and C. Weinstein (Eds.), Handbook of classroom management: Research, practice, and contemporary issues (pp. 97-125). New York: Erlbaum.

Emmer, E.T. \& Everton, C.M. (1981). Synthesis of research on classroom management. Educational Leadership, 38(4), 342-347.

Gump, P.V. (1967). The classroom behavior setting: Its nature and relation to student behavior (Final report). Washington, DC: US Office of Education. Bureau of Research. (ERIC Document Reproduction Service N ED 015 515).

Goffman, E. (1967). Interaction ritual. New-York: Doubleday.

Grice, P. (1975). Logic and conversation. In Cole, P. and Morgan, J. (Eds.) Syntax and semantics, Vol 3 (pp. 41-58). New York: Academic Press

Hastie, P.A. \& Siedentop, D. (1999). An Ecological Perspective on Physical Education, European Physical Education Review, 5(1), 9-29.

Hastie, P.A. \& Siedentop, D. (2006). The classroom ecology paradigm., In D. Kirk, M. O'Sullivan, and D. Macdonald (Eds.). Handbook of Research in Physical Education (pp. 214-225). London, Thousand Oaks, New Delhi: SAGE Publications Ltd.

Kirk, D. (2010). Physical Education Futures. London: Routledge, Taylor and Francis.

Kounin, J.S. (1970). Discipline and group management in classrooms. New York: Holt, Rinehart \& Winston

Leriche, J., Desbiens, J-F., Amade-Escot, C, \& Tinning, R. (Submitted). Compatibility and complementarity of ecological classroom ecology paradigm and didactique research tradition in physical education. Quest.

Leutenegger, F. \& Schubauer-Leoni, M.L. (2002). Les élèves et leur rapport au contrat didactique : une perspective de didactique comparée. Les Dossiers des Sciences de l'Éducation, 8, 73-86.

Lidar, M., Lundqvist, E., \& Östman, L. (2006). Teaching and learning in the science classroom - The interplay between teachers' epistemological moves and students' practical epistemology. Science Education, 90, 148-163.

Ligozat, F. \& Schubauer-Leoni, M.-L. (2009, July). The joint action theory in didactics: Why do we need it in the case of teaching and learning mathematics? In Proceedings of the Sixth Conference of European Research in Mathematics Education (pp. 83-92). http://educmath.inrp.fr/Educmath/recherches/actes-en-ligne/1wg9.pdf.

Ligozat, F. \& Leutenegger, F. (2012). Vergleichende Didaktik: Geschichte, Instrumente und Heraufsforderungen aus einer frankophonen Perspektive. Pädagogische Rundschau, 66(6), 751-771. 
Ligozat, F., Wickman, P. O., \& Hamza, K. M. (2011). Using Practical Epistemology Analysis to Study the Teacher and Students' Joint Actions in the Mathematics Classroom. In M. Pytlak, E. Swoboda, \& T. Rowland (Ed.), Proceedings of the 7th Congress of the European society for Research in Mathematics Education (pp. 2472-2481). Rzeszow: University of Rzeszow.

Marsenach, J. (1989). Les pratiques des enseignants d'EPS dans les collèges. Revue Française de Pédagogie, 89, 7-10.

McCaughtry, N., Tischler, A., \& Flory, S.B. (2008). The ecology of the Gym: Reconceptualized and Extended. Quest, 60, 268-289.

McDermott, R.P. (1977). Social relations as contexts for learning in school. Harvard Educational Review, 47(2), 198-213.

Mead, G.H. (1934). Mind, Self, and Society. Chicago: University of Chicago Press.

Mehan, H. (1979). Learning Lessons - Social organization in the classroom. Cambridge, MA: Harvard University Press.

MEN, (1998). Enseigner au collège : Education physique et sportive. Programmes et accompagnements. Paris : CNDP.

Mercier, A., Schubauer-Leoni, M.L., \& Sensevy. G. (2002). Vers une didactique comparée. Introduction. Revue Française de Pédagogie, 141, 5-16.

Quennerstedt, M., Öhman, J., \& Öhman, M. (2011). Investigating learning in physical education - a transactional approach. Sport, Education and Society, 16(2), 159-177.

Rink, J.E. (1994). Task presentation in pedagogy. Quest, 46, 270-280.

Schubauer-Leoni, M.L. (1986). Maître-élève-savoir : Analyse psychosociale du jeu et des enjeux de la relation didactique. Thèse de doctorat, non publiée, FAPSE, Université de Genève.

Schubauer-Leoni, M.L. \& Leutenegger, F. (2005). Une relecture des phénomènes transpositifs à la lumière de la didactique comparée. Revue Suisse des sciences de l'éducation, 27(3), 407-429.

Sensevy, G. (2007). Des catégories pour décrire et comprendre l'action didactique. In G. Sensevy \& A. Mercier (Dir.), Agir ensemble : l'action didactique conjointe du professeur et des élèves (pp. 13-49). Rennes : Presses Universitaires de Rennes.

Sensevy, G. (2009, January). Outline of a joint action theory in didactics. In Proceedings of the Sixth Conference of European Research in Mathematics Education (pp. 113-122). Lyon, France. Lyon, France. http://educmath.inrp.fr/Educmath/recherches/actes-enligne/1wg9.pdf

Sensevy, G. \& Forest, D. (2012). Semiosis process in instructional practice. In Proceedings of the $10^{\text {th }}$ ICLS 2011 conference (pp. 16-24), 2-6 July 2011, Sydney.

Siedentop, D. (2002) Ecological perspectives in teaching research, Journal of teaching in physical education, 21, 427-440.

Stake, R.E. (2000). Case studies. In N.K. Denzin and Y.S Lincoln (Eds.). Handbook of qualitative research (pp. 435-453). Thousand Oaks: Sage.2nd Ed.

Tiberghien, A. \& Venturini, P. (2015, forthcoming). Articulation des niveaux microscopiques et mésoscopiques dans les analyses de pratiques de classe à partir de vidéos. Revue de Didactique des Sciences et Techniques, 11, 
Tousignant, M. \& Siedentop, D. (1983). A Qualitative analysis of task structure in required secondary physical education classes. Journal of Teaching in Physical Education, 3(1), 47-57.

Venturini, P., \& Amade-Escot, C. (2014). Analysis of conditions leading to a productive disciplinary engagement during a physics lesson in a deprived area school. International Journal of Educational Research, 64, 170-183. DOI: 0.1016/j.ijer.2013.07.003

Verscheure, I. \& Amade-Escot, C. (2007). The gendered construction of physical education content as the result of the differentiated didactic contract. Physical Education and Sport Pedagogy, 12(3), 245-272.

Vygotsky, L. S. (1986). Thought and Language (A. Kozulin, Ed., Trans.). Cambridge, MA: MIT Press. (Original work published 1934).

Wickman, P.-O. (2012). A Comparison between Practical Epistemology Analysis and Some Schools in French Didactics. Éducation \& Didactique, 6(2), 145-159.

Wood, P. (1983). Sociology and the school. An interactionist viewpoint. London: Routlege, Kegan Paul. 